\title{
Algumas Observações sobre Foco, \\ CONTRASTE E EXAUSTIVIDADE ${ }^{1}$
}

\author{
Some observations on Focus, \\ Contrast and Exhaustivity
}

\author{
Sérgio de Moura Menuzzi*
}

\begin{abstract}
RESUMO
Neste artigo, discuto algumas ideias generalizadas sobre as relações entre foco, contraste e exaustividade, entre as quais: (i) a de que "foco informacional", "foco contrastivo" e "foco exaustivo" são diferentes em sua "composição de traços; (ii) a de que "contraste" e "exaustividade" são "traços" que podem ser adicionados ao foco; (iii) a de que há alguma diferença significativa (fonológica) entre acentos de foco informacional e foco contrastivo. Quanto às relações entre foco e contraste, procurarei mostrar que as condições em que se afirma que há "contraste" não são facilmente distinguíveis daquelas em que simplesmente temos foco informacional - o que também coloca em dúvida a ideia de que o "acento de contraste" seja distinguível do "acento de foco". Quanto à exaustividade, procurarei mostrar, seguindo Wedgwood (2005), que é uma "implicatura
\end{abstract}

${ }^{*}$ UFRGS/CNPq.

${ }^{1}$ Agradeço: a Pedro Henrique de Andrade e Mariana Teixeira Terra, meus BICs na UFRGS, por propiciarem as conversas em que surgiram as primeiras ideias aqui desenvolvidas; ao PPGL/ UFPR pelo convite de apresentar uma primeira versão deste material em seu III Forum de Produção Discente, em 31 de maio de 2012, e pelo feedback da audiência; a Marcelo Barra Ferreira e Fernanda Rosa da Silva, pelo convite para participar da banca de mestrado de Fernanda na USP, cujo trabalho forneceu elementos importantes para o que apresento aqui; aos organizadores do $60^{\circ}$ Seminário do GEL, realizado no FFLCH/USP, em junho de 2012, pelo convite que me permitiu apresentar uma segunda versão deste material, e à audiência do mesmo seminário, pelos comentários; finalmente, aos dois pareceristas da Letras pelas correções e sugestões. Usual disclaimers apply. O presente trabalho é financiado por bolsa de produtividade em pesquisa do $\mathrm{CNPq}$ (projeto "Estrutura informacional da frase e segmentação do discurso em DRT, novamente", Processo nr. 311160/2010-7). 
default" de foco; antes, é a ausência de exaustividade que exige ser "marcada" contextualmente. Além disso, o "traço característico" das clivadas parece ser uma "pressuposição de unicidade" associada à oração clivada - e não um "traço checado pelo constituinte clivado". Finalmente, explorando os efeitos de exaustividade, discutirei a questão de qual seria a "função básica" do foco: "evocar um conjunto de alternativas contextualmente relevante", segundo Rooth $(1985,1992)$, ou simplesmente "assinalar relevância", segundo Wedgwood (2005). Minha conclusão será a de que a posição de Rooth parece mais adequada.

Palavras-chave: foco; contraste; exaustividade; acento de foco; foco contrastivo.

\begin{abstract}
In this article, I discuss some widespread ideas concerning the relationship between focus, contrast and exhaustivity, among which: (i) the idea that "informational focus", "contrastive focus" and "exhaustive focus" are different in their "feature composition"; (ii) that contrast and exhaustivity are "features" that can be added to focus; (iii) that there is a significant (phonological) difference between the accents that mark informational focus and contrastive focus. Regarding the relationship between focus and contrast, I will try to show that the conditions under which contrast is claimed to be found are not easily distinguished from those in which simple informational focus is usually found. This raises doubts on the idea that there is a distinction between "accent of focus" and "accent of contrast". Concerning exhaustivity, I will try to show, following Wedgwood (2005), that it is a "default implicature" of focus, and that it is lack of exhaustivity that must be "marked" contextually. Besides, the "characteristic trait" of clefts seems to be a presupposition of unicity associated with the cleft clause, hence not a "feature to be checked by the cleft constituent". Finally, exploring exhaustivity, I will discuss the issue regarding the "basic function" of focus: whether it "evokes a contextually relevant set of alternatives", as proposed by Rooth $(1985,1992)$, or simply "signals relevant material", as proposed by Wedgwood (2005). I conclude in favor of Rooth's position.
\end{abstract}

Keywords: focus; contrast; exhaustivity; focus accent; contrastive focus. 


\section{INTRODUÇÃo}

Há algumas ideias, com origem em Chomsky (1971) e Jackendoff (1972), que são bastante difundidas na literatura sobre foco (ZUBIZARRETA, 1998; KISS, 1998; MIOTO, 2004; ROSA DA SILVA, 2012): (i) "foco informacional", "foco contrastivo" e "foco exaustividade" são diferentes - em sua "composição de traços", por exemplo; (ii) "contraste" e "exaustividade" podem ser adicionados ao foco - como "traços", por exemplo; (iii) por isso, possuem "construções especializadas" - especialmente, "focalização contrastiva" e "clivadas". Neste trabalho, meu objetivo é tentar qualificar, precisar, o que está correto em tais ideias.

Especificamente, argumentarei que foco, contraste e exaustividade são noções semântico-pragmáticas complexas e, por isso, têm propriedades muito diferentes - não adequadamente descritas por meio de recursos como "traços" discretos. Procurarei mostrar que o que define foco é a operação pragmática (marcada por acento) que sinaliza um "conjunto de alternativas contextualmente relevantes" (ROOTH, 1992, entre outros). Contraste, por outro lado, provavelmente cobre diferentes tipos de "ações verbais", coisas que se pode fazer com foco - como, por exemplo, o ato de fala de denegar asserções, pressuposições, etc. E exaustividade é uma inferência pragmática associada ao foco - uma implicatura no caso de foco informacional, possivelmente uma pressuposição no caso das clivadas (WEDGWOOD, 2005, WEDGWOOD et al., 2006). Sob esta ótica, provavelmente nem focalização contrastiva nem as clivadas são "especializadas" para expressar contraste e/ou exaustividade. Sugerirei, ainda, que não há diferença significativa entre os "acentos" (pitch accents) de foco informacional e foco contrastivo (KRAHMER; SWERTS, 2001; HARTMANN, 2008).

\section{TIPOS DE FOCO}

Em (1) abaixo, sintetizo uma classificação bastante conhecida na literatura sintática sobre foco (ZUBIZARRETA, 1998; KISS, 1998; MIOTO, 2004):

(1) a. Foco Informacional: "simplesmente fornece a informação solicitada” (MIOTO, 2004, p. 169); isto é, é simplesmente a asserção de uma proposição.

b. Foco Contrastivo: "envolve contraste ou correção de informação anterior" (id.); isto é, é a asserção de uma proposição e a negação de (pelo menos) uma proposição alternativa. 
c. Foco Identificacional: envolve "informação exaustiva" (id.), isto é, a asserção de uma proposição e a exclusão das demais proposições alternativas.

Essas noções são ilustradas em (2), (4) e (6) abaixo; em (3), (5) e (6), uso a "estrutura da asserção" de Zubizarreta para explicitar as leituras:

(2) Foco informacional

A: O que o João comprou?

B: O João comprou UM CARRO.

(3) Asserção 1: Existe um x tal que o João comprou x.

Asserção 2: $0 \mathrm{x}$ tal que o João comprou x é um carro.

(4) Foco contrastivo

A: (Você sabe da última?) O João comprou UM AVIÃo.

B: O João comprou UM CARRO (, e não UM AVIÃO).

(5) Asserção 1: Existe um x tal que o João comprou x.

Asserção 2: É falso que $0 \mathrm{x}$ tal que o João comprou x é um avião \& $\mathrm{O} \times$ tal que o João comprou x é um carro.

(6) Foco identificacional

A: O João me disse que tinha comprado algum veículo um carro, uma moto...

B: Foi UM CARRO que o João comprou.

(7) Asserção 1: Existe um $\mathrm{x}$ tal que o João comprou $\mathrm{x}$.

Asserção 2: $\quad 0 \times$ tal que o João comprou $x$ é um carro \&

É falso que exista y, y um veículo e y ${ }^{1} \mathrm{x}$, tal que João comprou . $^{2}$

${ }^{2}$ Nas representações encontradas em Mioto (2004), a asserção 2 de (7) é assim expressa: "O x tal que o João comprou x é um carro \& Não existe y, y um veículo e y ${ }^{1} \mathrm{x}$, tal que João comprou y." Isto é, na versão de A2 acima, substituí "Não existe" por "É falso que". Com isso, quero justamente trazer à tona o fato de que a "negação" em A2 de (6) e em A2 de (7) não deveriam ser diferentes: em se tratando, ambas, de operadores sobre conteúdos proposicionais, Não e É falso que expressam exatamente a mesma função semântica. $\mathrm{Na}$ verdade, provavelmente a motivação de Mioto para usar É falso que em A2 de (6) e Não (existe y ...) em A2 de (7) é que as intuiu como "negações" diferentes - como de fato são: a primeira está relacionada a um ato de fala, uma denegação; a segunda, sim, é apenas um operador sobre um conteúdo proposicional. O problema das representações em (6) e (7) reside justamente em não fazerem a distinção. Ver a discussão da seção 3 abaixo. 
É importante ter em mente que a classificação acima é simultaneamente "funcional" $e$ "formal" - presume que os diferentes focos não apenas são usados em contextos diferentes, mas também têm características de forma diferentes. Zubizarreta (1998), seguindo Chomsky (1971) e Jackendoff (1972), acredita que a "projeção de foco" é uma propriedade que deriva do caráter "formal" do foco informacional não marcado - que seria o foco que coincide com a proeminência default do acento nuclear, diferente do foco contrastivo; isto é, a foco informacional e foco contrastivo difeririam quanto à estrutura prosódica. Para Kiss (1998), o foco identificacional tem sintaxe diferente do foco informacional: tanto a posição pré-verbal em húngaro quanto as clivadas em inglês envolveriam uma categoria funcional específica na periferia esquerda da frase. ${ }^{3}$

Há outras "tipologias", sendo algumas explicitamente "funcionais" - isto é, em que as diferenças entre "focos" são derivadas contextualmente a partir da semântica/pragmática básica de "foco informacional" (HARTMANN, 2008, baseada na semântica do foco de ROOTH, 1985, 1992; ver a seguir). Mas há forte tendência para a ideia de uma relação íntima entre "função focal" e "construção focal especializada". Por exemplo, recentemente, Gussenhoven afirmou: "I take formal characteristics rather than contextual differences to be the criterion for recognizing a focus type" (2007, p. 90). A extensão da tipologia proposta por ele deixa claro o risco desta linha de abordagem:

(8) Tipologia "Formal" de Gussenhoven (2007)

a) foco apresentacional

b) foco corretivo (= foco contrastivo)

c) foco contrapressuposicional

d) foco definicional

e) foco contingencial

f) foco de reativação (= tópico contrastivo)

g) foco identificacional

A linha que vou sugerir no resto deste artigo é oposta à que presume que há diversidade de "funções de foco" - ao contrário, sugerirei que as

${ }^{3}$ Contra a análise de Kiss (1998), ver Wedgwood (2005). De fato, contra a análise dos efeitos de exaustividade como acarretamentos das clivadas, ver Horn (1982). Quanto ao argumento tradicional de que é preciso distinguir "foco informacional" de "foco contrastivo" porque apenas o primeiro é "projetável”, ver discussão em Lambrecht (1994) e Wedgwood (2005), para quem há diferenças pragmáticas relevantes entre "foco amplo" (ou "de predicado") e "foco estreito" (ou "de argumento"), que poderiam explicar esta diferença. Confesso aqui que ainda não tenho certeza de que estas explicações são satisfatórias. 
distinções formais são poucas, e as funcionais, em larga medida, derivadas pragmaticamente. Mas, antes de começar minha argumentação, devo mencionar uma outra "função informacional marcada" que, definitivamente, me parece independentemente necessária, embora eu não possa discuti-la neste artigo: a de "tópico contrastivo", cuja curva entoacional característica é a de elementos deslocados à esquerda, como Ontem em (9B):

(9) A: Quem o João encontrou ontem?

B: Ontem (,) ele encontrou A MARIA.

A MARIA (ele encontrou ontem).

\# A Maria (,) ele encontrou ontem.

A meu ver, a inaceitabilidade de $A$ Maria (com a entoação mencionada) em (9) demonstra que "tópicos contrastivos" não podem ser confundidos com a função de "foco", nem podem ser assimilados a ela. (Para discussão adicional, ver BÜRING, 2003; MENUZZI; RODRIGUES, 2010; RODRIGUES; MENUZZI, 2011; entre outros.) Assim, a direção geral do presente artigo é no sentido de que as noções de "foco informacional", "foco contrastivo" e "foco exaustivo" são redutíveis à de "foco", em interação com informações contextuais; mas a existência de "tópicos contrastivos" indica que "foco" não é a única função informacional marcada por proeminência prosódica.

Como resultado da ideia de que há relação íntima entre "função focal" e "construção focal especializada", frequentemente assume-se que a "representação gramatical", especialmente sintática, das construções correspondentes é "especificada" para tais distinções pragmático-semânticas. Por exemplo, Mioto (2004), expressando as distinções de Zubizarreta e Kiss numa abordagem cartográfica (RIZZI, 1997), propõe a seguinte análise para os diferentes focos apresentados em (2)-(7): (a) são distinguidos pelos traços [ \pm contrastivo], [ \pm exaustivo]; (b) em português, focos especificados para [+contrastivo] ou [+exaustivo] são checados em FocP na periferia de IP; e (c) foco informacional ("in situ") é checado em FocP na periferia de VP. O sistema resultante é algo como (10) (esquema adaptado do proposto por Mioto, 2004, em (10), p. 175):

(10) Tipo de Foco:

Especificação Gramatical: Construções:

a) foco informacional: [+foco, -contrastivo,

$$
\text { -exaustivo] foco in situ }
$$

b) foco contrastivo: [+foco, + contrastivo,

+exaustivo] FC, clivadas, foco in situ

c) foco exaustivo: [+foco, - contrastivo,

+ exaustivo] clivadas, foco in situ

d) lacuna: [+foco, + contrastivo,

-exaustivo] 
Mioto admite que "foco in situ" pode ser usado para expressar todos os focos, embora para isso precise ser "adicionalmente especificado" nas representações sintáticas e semânticas correspondentes. É interessante observar também que, por alguma razão, há uma lacuna no sistema: não há foco [+contrastivo] que seja [-exaustivo]; embora Mioto (2004) não a discuta em detalhe, veremos na seção seguinte que há explicação para ela.

\section{Contraste e exaustividade}

Um primeiro problema para a descrição dos efeitos de "contraste" e de "exaustividade" é que eles não são facilmente distinguíveis se representados como em (5) e (7). Para ver isso, é preciso que se explicite um pouco mais do "significado" do foco. Em geral, as análises correntes da semântica e da pragmática associadas ao foco recorrem a alguma versão da "semântica de alternativas" proposta por Rooth $(1985,1992)$, que parte da ideia básica de que "foco informacional" codifica a "informação solicitada por uma questão". Semanticamente, questões são "conjuntos de proposições alternativas contextualmente relevantes". Rooth chama este conjunto de alternativas de "valor semântico ordinário" de uma pergunta; o conjunto é constituído pela substituição da expressão QU pelos termos que poderiam, contextualmente, fornecer uma resposta à pergunta, como em (11) abaixo:

(11) $\|$ O que o João comprou? $\|^{\circ}=$ \{João comprou um carro, João comprou um avião, João comprou uma moto, etc. $\}=\mathrm{A}_{\mathrm{c}}$ em que $\mathrm{A}_{c}$ é "contextualmente determinado".

"Foco informacional" é, portanto, a "asserção de uma proposição que pertence a um conjunto de proposições alternativas contextualmente determinado". A condição de "congruência" entre pergunta e resposta pode, agora, ser definida em termos do "valor semântico ordinário" de perguntas e do "valor focal" da resposta (ver também BÜRING, 1997, 2003):

$\| \mathrm{O}$ João comprou UM CARRO $\left\|^{\mathrm{F}} \subseteq\right\| \mathrm{O}$ que o João comprou? $\|^{\mathrm{O}}$

Para o que segue, é crucial reiterar: o "foco informacional" corresponde, na verdade, a uma proposição que pertence a um conjunto de proposiçóes alternativas contextualmente relevantes; é aquela que é assertada pelo falante, isto é, aquela que é enunciada como verdadeira pelo falante, que busca com isso integrá-la ao "common ground". 
Agora, retornemos às noções de "foco contrastivo" e de "foco exaustivo".

Como vemos em (4), o exemplo canônico de "foco contrastivo" envolve a asserção de uma proposição e acarreta ou implica a negação de uma alternativa contextual à proposição assertada. Admita-se que:

(i) a proposição assertada e a negada formam o conjunto de alternativas contextualmente relevantes, isto é, em (4) acima, $A_{c}$ corresponde ao seguinte conjunto de alternativas: \{João comprou um carro, João comprou um avião\});

(ii) "exaustividade" é definida com relação a este conjunto de alternativas contextualmente relevantes: é a falsidade de todas as alternativas exceto uma, a expressa pela sentença (como em Kiss, 1998) - isto é, corresponde à negação de todas, salvo a assertada.

Se (i) e (ii) são verdadeiras, é inevitável concluir que "foco contrastivo" acarreta ou implica "foco exaustivo".

Por outro lado, sendo exaustividade e contraste caracterizados como acima indicado, obviamente exaustividade presume contraste: sendo a verdade da alternativa expressa pela sentença declarativa e a falsidade de todas as demais, presume a asserção da primeira e a negação das demais. Note-se que isso explica a lacuna em (10d) acima.

Em resumo, parece que chegamos a um paradoxo: a literatura costuma identificar duas noções de "foco" diferentes - a de "foco contrastivo" e a de "foco exaustivo"; mas, do modo como são normalmente caracterizadas, parecem ser redundantes já que se implicam mutuamente. Como a observação de que são tipos de focos diferentes parece intuitivamente correta, conclui-se que a caracterização acima das duas noções é que não é adequada. A pergunta, portanto, deve ser: o que distingue, mesmo, "foco contrastivo" de "foco exaustivo"?

A fim de distingui-las, a primeira coisa a observar é que a diferença não pode residir na "negação de conteúdos proposicionais", pois ambas as noções de "contraste" e "exaustividade", como caracterizadas acima, envolvem isso.

Embora ambas envolvam a negação de algum conteúdo proposicional, é importante observar que apenas "exaustividade" é caracterizada em termos estritamente semânticos, isto é, em termos que podem ser caracterizados como parte das "condições de verdade" da sentença - e não das "condições de felicidade" do enunciado: é uma relação que se estabelece entre a verdade e a falsidade - portanto, a negação - de proposições que constituem um conjunto de alternativas. "Negação", neste sentido, é apenas um elemento da representação semântica das proposições (um operador que toma a sentença como argumento, e denota a função de valores de verdade a valores de verdade). 
Por isso, a exaustividade, como acima concebida, pode ser asserta$\mathrm{da}$, pressuposta, implicada, sem que acarrete ou implique necessariamente "correção de um conteúdo proposicional" assertado (ou implicado, ou pressuposto, ou esperado) pelo interlocutor. É o que acontece em (6), em que não há propriamente "rejeição de algum conteúdo proposicional" assertado, pressuposto ou esperado pelo interlocutor, já que este expressa, precisamente, estar em "estado de não conhecimento" em relação às alternativas contextuais. Na verdade, o "foco exaustivo" em (6) tem uma função muito próxima à do foco informacional tal como este é concebido correntemente (cf. discussão de (11) e (12) acima). Voltarei a esta questão nas seções seguintes.

Já o "foco contrastivo", se caracterizado como envolvendo a "correção" de um conteúdo proposicional, não apenas implica implicitamente, ou mesmo asserta explicitamente, a exaustividade do conteúdo proposicional que veicula; em (4) acima, faz isso negando o conteúdo proposicional de alternativas que foram previamente assertadas (implicadas, etc.) pelo interlocutor. Se este elemento de "correção" é característico do contexto típico de "contraste", então contraste não pode ser caracterizado em termos puramente semânticos; antes, envolve condições de felicidade que são contextuais e relativas aos atos de fala ou às atitudes proposicionais de outrem. Em outros termos, "contraste", neste sentido, não é a mera asserção (da "negação") de um conteúdo proposicional; é um ato de fala próprio, uma denegação - uma asserção contrária ao que é assertado (ou, talvez, pressuposto ou esperado, etc.) no contexto.

Dessa incursão pelas noções de "exaustividade" e "contraste" tal como se revelam nos contextos típicos que as ilustram, concluo que, se há algo que distingue "contraste" de "exaustividade", não é a "negação de um conteúdo proposicional": tanto "exaustividade" como "contraste" envolvem a negação de conteúdos proposicionais. Mas "contraste" envolve mais: não é apenas a negação de certos conteúdo proposicionais, mas a "denegação" deles - isto é, é o ato de fala de assertar uma alternativa contrária a conteúdos que foram previamente assertados, ou são pressupostos, etc., no contexto.

Neste ponto, duas perguntas se colocam:

(i) Assim distinguidos, será que "contraste" e "exaustividade" de fato correspondem ao que, intuitivamente, se entende por estas noções? Será que continuam cobrindo todos os casos que a literatura utiliza para ilustrar estas noções?

(ii) E, sendo caracterizados como acima fiz, poderiam ser "adicionados" como "categorias informacionais/pragmáticas discretas" ao foco, como a literatura sintática parece presumir?

No que segue, tentarei responder, ainda que parcialmente, a estas questões. Mas antecipo aqui minhas conclusões: (i) "contraste" não é uma 
categoria funcional discreta e provavelmente não pode ser "codificada" independentemente de informações contextuais (tais como pressuposições, implicaturas, condições de felicidade de atos de fala); (ii) "exaustividade" até pode ser uma categoria funcional discreta; mas, sendo esta a categoria, não é o que distingue o "foco informacional" de sentenças canônicas do "foco exaustivo" das clivadas.

\section{FOCO E CONTRASTE}

Na presente seção, pretendo discutir algumas das propriedades do "foco contrastivo". Meu primeiro objetivo é verificar se a noção de contraste que identificamos na seção precedente cobre adequadamente todos os casos que a literatura considera como de foco contrastivo; e se consegue distingui-los de outros que, provavelmente, não seriam tidos como contrastivos. Pretendo, também, avaliar a ideia de que "contraste" é um "elemento funcional" (semântico ou pragmático) que pode ser isolado e, sendo isolável, pode ser "adicionado" ao foco. Minha conclusão será negativa: o conjunto de casos que a literatura considera como de "foco contrastivo" envolve diferentes fatores e não parece haver um componente unificador identificável. ${ }^{4} \mathrm{~A}$ discussão tocará, finalmente, num outro ponto, relacionado à assunção de que noções como "contraste" e "exaustividade" possuem "construções especializadas": frequentemente se postula a existência de um "acento" (na verdade, pitch accent ou melodia tonal) específico para "foco contrastivo" (por exemplo, PIERREHUMBERT; HIRSCHBERG, 1990); mas há, também, sérias dúvidas sobre se é possível distingui-lo fonologicamente de outros "acentos" da frase (KRAHMER; SWERTS, 2001; HARTMANN, 2008). Procurarei mostrar que a comparação de casos de "foco contrastivo" com casos muito próximos de "foco informacional" fornece uma razão adicional para tais dúvidas.

Na seção anterior, vimos que "foco contrastivo", em suas ocorrências canônicas, envolve a "correção" de um conteúdo proposicional pela asserção de uma alternativa contrária, e é tipicamente ilustrado em contextos

${ }^{4}$ Um parecerista sugere outra linha de argumentação: se o elemento de "contraste" fosse "isolável", deveria ocorrer independentemente da função de foco. Embora o raciocínio tenha fundamento, é preciso ter em mente que tudo depende do que se entende, exatamente, por "contraste". Por exemplo, suponha que "contraste" seja - como estamos discutindo - "correção" de um termo em uma proposição previamente assertada, pressuposta etc. Neste caso, é difícil imaginar em que situação "contraste" poderia ser independente de foco, já que a "correção" consiste exatamente em fornecer "informação nova" acerca de um termo em uma proposição "dada". Note-se, entretanto, que "contraste como correção", ainda assim, é "isolável" da função pura e simples de "foco": esta nem sempre envolve "correção" de algum termo em uma proposição previamente assertada, pressuposta etc. 
em que o conteúdo proposicional contrariado foi previamente assertado, como em (4). Também sugeri, embora sem exemplificar, que a alternativa denegada não precisa ser diretamente assertada no contexto: casos como (12) abaixo também são apresentados como "foco corretivo" e, de fato, parecem ser enunciados denegativos (ZUBIZARRETA, 1998, n. 18 do cap. 1, p. 163; ROSA DA SILVA, p. 21): é o que indica a possibilidade de uso do "Não" de rejeição. Note-se que, em (12), o conteúdo denegado não chega a ser uma pressuposição do interlocutor A; é no máximo uma expectativa dele:

(12) A: O João chegou?

B: (Não,) O PAULO chegou.

Outro exemplo tradicionalmente tido como de "foco contrastivo" é o que se ilustra como o enunciado de B em (13) abaixo. É exatamente o que Erteschik-Shir (2007) chama de "foco contrastivo"; para Hartmann (2008), é um dos casos de "foco contrastivo" - o que ela chama de "foco seletivo":

(13) A: Quem chegou, o João ou o Paulo?

B: (*Não,) O PAULO chegou. (Inferência: O João não chegou.)

B': Foi o PAULO (que chegou).

Observe-se agora que (14) abaixo parece essencialmente o mesmo caso, salvo que exige um pressuposto contextual: que Paulo seja um dos alunos relevantes. Tendo função contextual similar a de (13B), esperaríamos que também fosse um caso de "foco contrastivo".

(14) [Contexto: A e B compartilham a informação de que Paulo é um dos alunos.] A: Quais dos alunos chegaram?

B: (*Não,) O PAULO chegou. (Inferência: Outros alunos não chegaram.)

B': \#Foi o PAULO (que chegou).

Mas há um problema em chamar de "foco contrastivo" tanto (14) quanto (13) - que, como mencionei, é tido pela literatura como exemplo de "foco contrastivo". Embora (13) e (14) sejam exaustivos por implicar a negação das alternativas contextuais, não parecem, à primeira vista, "corretivos"; e claramente não são denegativos, como o demonstra a impossibilidade de uso de "Não" de rejeição. Assim, por que incluir (13) entre os exemplos de "foco contrastivo", e não incluir (14)? E, se ambos excluem as demais alternativas contextuais, por que não incluir ambos no que se chama de "foco exaustivo" ou "identificacional"? 
Haveria mais uma razão para dizer que (13) é exaustivo (ou identificacional): no mesmo contexto, poder-se-ia usar uma clivada com efeitos contextuais equivalentes, como mostra (13B'). Mas, curiosamente, a clivada não seria feliz no contexto em (14). (15) abaixo elucida esta diferença entre (13) e (14):

(15) A: Qual dos alunos chegou?

B: O PAULO chegou.

(Inferência: Outros não chegaram.)

B': Foi o PAULO (que chegou).

Em (15), como em (13) - e diferentemente de (14) - a clivada é aceitável. O que a oposição (13B')-(15B’) versus (14B') revela é: se, em algum destes casos, há algo próximo a "foco corretivo", é em (14). Neste exemplo, parece haver "correção" de uma pressuposição contextual: a de que mais do que uma das alternativas pode ser verdadeira. Em (13) e (15), a pressuposição de que apenas uma das alternativas é verdadeira é compartilhada por A e B - é ela, na verdade, que autoriza o uso de clivadas em ambos os contextos. ${ }^{5}$ Logo, não há qualquer tipo de correção, sequer de expectativas, do interlocutor. Evidentemente, em (15) trata-se, simplesmente, de "foco informacional", sem mais nem menos. Ou seja: a única razão para se dizer que (13) é um caso de "foco contrastivo" é o fato de que se trata, como nos casos de "foco corretivo", de um foco "anafórico": o foco se dá na presença prévia explícita de uma alternativa (que, por não ser a assertada, é implicitamente negada). Mas não há "correção" no sentido de recusa de uma alternativa contextualmente assertada, pressuposta ou esperada.

Toda esta discussão dos exemplos (13), (14) e (15) coloca, me parece, questões prementes para a distinção entre "foco contrastivo" e "foco informacional": (i) o fato de uma asserção excluir uma alternativa contextualmente presente, mas não rejeitar a asserção ou a pressuposição ou mesmo a expectativa desta proposição, é suficiente para dizer que temos "foco contrastivo" - como em (13)? (ii) E por que (14) não é mencionado como um caso de "foco contrastivo", envolvendo, como envolve, a "correção" de um conteúdo proposicional pressuposto contextualmente? (iii) E, sendo (13) mais próximo, pragmaticamente, a (15) do que a (14), não seria (13) na realidade apenas um caso de "foco informacional"? Finalmente, há um correlato formal para todas estas questões: (iv) há, realmente, diferença perceptível nos "acentos" atribuídos a (13), (14) e (15) - de modo que nos permita distinguir o caso tido como de "foco contrastivo", isto é, (13), do

\footnotetext{
${ }^{5}$ Estas observações sobre o uso das clivadas serão importantes para a discussão da noção de "exaustividade" e serão retomadas na próxima seção.
} 
caso em que temos claramente "foco informacional", isto é, (15)? A minha conclusão geral acerca de todas estas questões, quando refletimos sobre (13), (14) e (15), é que a distinção entre "foco contrastivo" e "foco informacional" parece muito mais incerta do que se presume, e isso se estende à distinção entre os acentos de "foco contrastivo" e "foco informacional".

De modo similar, os exemplos precedentes parecem indicar que a relação entre "contraste", "correção" e "denegação" é complexa. Para reforçar este ponto, considere (16) abaixo, comparando-o com (14) acima - isto é, com o caso que, entre (13), (14) e (15), melhor corresponderia a "contraste como correção".

16) [Contexto: A e B compartilham a informação de que Paulo é um dos alunos.] A: Os alunos chegaram?

B: (Não,) O PAULO chegou. (Inferência: Outros alunos não chegaram. $^{6}$

Em primeiro lugar, (16) mostra o mesmo efeito de exaustividade que se vê em (14) - dada a mesma pressuposição, qual seja, a de que Paulo é um dos alunos. Em segundo lugar, o "caráter corretivo" é muito similar: ambos implicam a negação de um certo conteúdo proposicional entretido por outrem no contexto - o de que mais do que uma das alternativas contextuais é verdadeira ou pode ser verdadeira. Mas há uma diferença importante entre (16) e (14): no caso de (14A), este conteúdo é uma pressuposição; e no caso de (16A), é mera expectativa potencial. Se a relação pertinente é entre asserção e "grau de crença ou assertibilidade" da alternativa rejeitada pela asserção, poder-se-ia esperar que o "contraste" fosse maior em (14) do que em (16).

Mas há outra diferença importante entre os dois casos. Como ato de fala, só (16A) conta como uma denegação direta: a resposta a uma pergunta de Sim/Não é ou uma asserção ("Sim, ..."), ou uma denegação (“Não, ..."). Portanto, se a relação pertinente é entre denegação e contraste - e não entre asserção e "grau de crença ou assertibilidade" da alternativa rejeitada -, (16B) deveria ser "mais contrastiva" que (14B). A pergunta é: pode-se detectar, intuitivamente, alguma diferença de "grau de contraste" entre (14) e (16)? Ela se manifesta, por exemplo, por meio de diferenças na "ênfase" dada ao acento?

${ }^{6}$ Um dos pareceristas observa que, de acordo com seus julgamentos, só acento de foco contrastivo não é suficiente para invocar o efeito de exaustividade (isto é, a inferência "Os outros alunos não chegaram"). Para este parecerista, no contexto em (16), a expressão de exaustividade exige a presença de uma partícula como só ou apenas. O julgamento que reporto no texto, por outro lado, foi confirmado por 4 falantes (de meu dialeto). 
Vale explorar um pouco mais (16) com relação ao "acento de contraste". (16) conta como uma "denegação" porque, se apenas Paulo chegou, isso é condição suficiente para que "Os alunos chegaram" seja falsa. Evidentemente, o mesmo não é verdade para (17A) abaixo, razão pela qual (17B) conta como uma asserção - na verdade, é, novamente, "foco informacional" apenas:

(17) A: Algum dos alunos chegou?

B: (Sim,) O PAULO chegou.

Digamos que, intuitivamente, (16B) seja "foco contrastivo" (como, ou "um pouco mais" que, (14B)) e que (17B) seja "foco informacional": há diferença necessária nos "acentos" e curvas entoacionais correspondentes a (16B) e (17B)? Eu diria que pode haver, mas ela não é necessária.

Para encerrar a discussão sobre a relação entre denegação, contraste e acentos, considere o caso abaixo, adaptado de Rosa da Silva (2012, (20), p. 23):

(18) A: O João chegou?

B: Sim, TODO MUNDO chegou.

B': Não, TODO MUNDO chegou.

A meu ver, tanto (18B) quanto (18B') parecem "contrastivos". E, embora apresentem diferenças de ato de fala ((18B) é uma asserção confirmativa enfática, (18B') é uma denegação corretiva), com consequências pragmáticas diferentes, não me parece que tais diferenças sejam necessariamente expressas por meio de "acentos" diferentes. ${ }^{7}$

De toda a discussão desta seção, creio que podemos concluir que:

(i) É possível que "contraste" esteja ligado a "denegação" ("correção"), mas certamente este não é o único elemento que autoriza uma leitura "contrastiva" do foco em um certo contexto - ao menos quando consideramos os casos de "foco contrastivo" apresentados na literatura. ${ }^{8}$

${ }^{7}$ Por exemplo, a asserção (18B) não parece ser "implicativa”, a denegação (18B') sim: ver a discussão de Rosa da Silva (2012) sobre a aparente quebra da máxima de relevância com os casos do que ela chama de "foco sobreinformativo". Os exemplos em (18) possuem outras consequências importantes, especialmente para a caracterização apropriada dos chamados "efeitos de exaustividade", mas não poderei explorar estas consequências aqui.

${ }^{8}$ Muitos trabalhos na literatura sobre estrutura hierárquica do discurso e sobre "relações de coerência" entre dois segmentos textuais têm tentado caracterizar a relação retórica de "contraste" também em termos de "denegação": ver, por exemplo, Umbach (2005), Spenader e Maier (2009). Mas creio que tais análises não são extensíveis, em regra, aos casos que a literatura sobre "foco" considera como de "foco contrastivo". Uma das razões é que, na literatura sobre "contraste retórico", a conjunção mas é tida como um diagnóstico para a presença da relação. Mas casos como (12) e (13), que a literatura considera como típicos de "foco contrastivo", não são compatíveis com o uso de mas, obviamente. 
(ii) Distinções de contraste parecem ser "gradientes", embora raramente se discuta isso na literatura; por isso, "contraste" parece de fácil percepção em certos casos isolados (por exemplo, (4) acima). Mas, quando se compara tais casos com outros muito próximos, percebe-se que há situações de fronteira que tornam muito difícil distinguir "foco contrastivo" de "foco informacional".

(iii) O "contraste" parece variar de acordo com um conjunto grande de informações pragmáticas: atos de fala, pressuposições, implicaturas, exaustividade e a presença de alternativas explícitas no contexto imediato. Parece difícil que este conjunto de elementos pragmáticos possa ser unificado por algum traço discreto de significado "[+contraste]" que tenha maior poder explicativo que a tradicional noção de "ênfase", por exemplo. Isto é, parece que a noção de "foco contrastivo" ainda é apenas um termo descritivo para um conjunto de efeitos pragmáticos associados ao foco que precisam ser melhor estudados.

(iv) Concomitantemente, quando se considera os casos de fronteira lado a lado com casos presumivelmente claros de "foco contrastivo" e de "foco informacional", não é evidente, de modo algum, que haja diferença significativa (fonológica!) entre os "acentos" (pitch accents) que marcam a distinção "foco informacional" e "foco contrastivo". Isso apenas confirma dúvidas já veiculadas na literatura sobre a entoação de foco (ver, por exemplo, KRAHMER; SWERTS, 2001; HARTMANN, 2008).

\section{Foco E EXAUSTIVIDADE}

Na seção precedente, procurei mostrar que a distinção entre "foco informacional" e "foco contrastivo" parece ter um caráter gradual, e é certamente menos segura do que normalmente se presume, seja do ponto de vista de seus efeitos pragmáticos, seja do ponto de vista de sua forma de expressão (isto é, do "acento" associado). Disso, concluí que é difícil que "contraste" seja algum tipo de informação semântica ou pragmática "discreta" (representável por algo como um "traço sintático"), que possa ser adicionada ao foco. Nesta seção, o que pretendo mostrar é que, de modo similar, a diferença entre "foco informacional" e "foco exaustivo" também parece inapropriadamente caracterizada pela ideia de "adição de informação pragmática ou semântica discreta" (isto é, representável pelo traço "[+exaustivo]") ao foco.

Tal como acontece com a distinção entre "foco contrastivo" e "foco informacional", também a distinção entre "foco informacional" e "foco exaustivo", ou "identificacional”, está bastante sedimentada na literatura 
(especialmente, a partir de Kiss, 1998), e tende a se refletir nas seguintes ideias: (i) a "exaustividade" (isto é, a exclusão de alternativas que não a assertada) não seria um "traço inerente" de foco informacional; (ii) mas poderia ser "adicionada" ao foco, resultando no "foco exaustivo"; e (iii) por outro lado, a "exaustividade" seria "traço inerente" das construções de "foco identificacional", que incluiriam as clivadas do inglês (e a chamada "posição de foco" do húngaro, segundo Kiss, 1998). Os exemplos em (19) e (20) abaixo ilustram o que a literatura presume ser o contraste pragmático básico entre "foco informacional" e "foco exaustivo":

(19) [Contexto: B está contando a A que foi a uma festa super legal, etc.] A: Quem você encontrou lá?

B: Eu encontrei O PAULO lá.

B': \# Foi O PAULO que encontrei lá.

(2) A: Quem chegou, o João ou o Paulo?

B: O PAULO chegou.

B': Foi O PAULO (que chegou). ${ }^{9}$

Numa primeira aproximação, pode-se dizer que, no contexto em (19), o enunciado de B não implica que B encontrou só o Paulo - é pragmaticamente implausível que uma pessoa vá a uma festa e encontre apenas uma outra pessoa; estaríamos diante de uma festa de duas pessoas... Em (20), por outro lado, o enunciado de B claramente implica que a alternativa não assertada (a de que João chegou) está excluída. Isto é, o enunciado de B em (19) não parece "exaustivo em relação a alternativas contextualmente relevantes", mas em (20) sim. Concomitantemente, o uso de uma clivada para expressar o mesmo conteúdo só parece adequado em (20).

${ }^{9}$ Um dos pareceristas observa que o contraste entre as clivadas em (19B') e (20B') poderia, na verdade, ter origem numa assimetria observada por Belletti (2009) em francês: nas palavras do parecerista, "há uma diferença entre a clivagem do sujeito e a do objeto como resposta a questões de foco informacional (aparentemente, apenas questões sobre o sujeito podem ser respondidas com uma sentença clivada)". De fato, assimetria semelhante foi observada também em português brasileiro (ver, por exemplo, QUAREZEMIN 2009). Mas, a meu ver, esta observação não explica o contraste entre (19B') e (20B'): como vemos em (i) abaixo, a clivada permanece insatisfatória num contexto como (19B'), ainda que seja de sujeito; e, como vemos em (ii), a clivada permanece aceitável em um contexto como (20B'), ainda que se trate de uma clivagem de objeto:

(i) [Contexto: B está contando a A que foi a uma festa super legal, etc.]

A: Quem 'tava lá?

B: O PAULO ('tava lá). B': \# Era O PAUlo (que ‘tava lá).

(ii) A: Quem falou com você, o João ou o Paulo?

B: O PAULO (falou comigo). B': Foi O PAULO (que falou comigo). 
Assim, casos como (19) e (20) parecem indicar que é preciso distinguir "foco informacional não exaustivo" de "foco informacional exaustivo" isto é, foco informacional simples de foco informacional a que foi adicionada a exaustividade. Entretanto, Wedgwood (2005) faz duas observações fundamentais, que parecem desmanchar esta fronteira. A primeira delas é a de que a mera presença situacional de um conjunto de alternativas relevantes é suficiente para fazer com que "foco informacional" implique "exaustividade" - a negação das alternativas que não a assertada. Por exemplo, ao assertar que João quer café em (21) abaixo, B implica que ele não quer nenhuma das outras alternativas que poderia querer no contexto:

(21) [Contexto: várias pessoas em torno de uma mesa com café, chá, bolachas, etc.]

A: O que o João quer?

B: (O João quer) CAFÉ. (Inferência: João não quer chá, bolachas, etc.)

B': \# É CAFÉ (que o João quer).

B": Ele quer CAFÉ. Aliás, acho que ele também quer BOLACHAS.

Mas note-se que o efeito de "exaustividade contextual" do enunciado (21B) é uma inferência pragmática que poderia ser cancelada: pode ser corrigida sem evocar autocontradição, como se vê em (21B'). Finalmente, o contexto em (21) é importante, também, porque demonstra que a possibilidade de expressar "exaustividade contextual" não é condição suficiente para o uso da clivada, como o mostra a inadequação de (21B').

Portanto, a primeira observação fundamental de Wedgwood é a de que foco informacional, sob condições pragmáticas adequadas, também veicula "exaustividade". A segunda observação fundamental é a de que, num contexto em que há um conjunto de alternativas relevantes, é o foco não-exaustivo que deve ser "marcado" - isto é, se outras alternativas são verdadeiras, isso deve ser sinalizado, como em (22B').

(22) [Contexto: A e B sabem quem são os "amigos patetas do João".]

A: A Maria me contou que disseram pr'o João ir na festa com os amigos patetas dele. Você sabe quem ele levou?

B: Ele levou O PAULO. (Inferência: Ele não levou os demais patetas.)

B': Ele levou O PAULO e mais dois/os outros/etc. 
De casos como (21) e (22), Wedgwood conclui que, na presença de um conjunto de alternativas relevantes, se não marcado para o contrário, "foco informacional" implica exaustividade. Isto é: exaustividade é, na verdade, uma "inferência default" de foco informacional. Isso claramente tem consequências para a distinção entre "foco informacional" e "foco exaustivo": não é o caso que, nas situações mais comuns em que se precisa expressar "exaustividade", é preciso ou "adicionar" esta informação ao foco, ou utilizar uma expressão "especializada" para exaustividade, que seria a clivada. De fato, o contexto em (21) mostra que, nos contextos em que o requisito de felicidade se limita a ser a asserção de exaustividade, "foco informacional" seria adequado, mas não uma clivada.

$\mathrm{Na}$ verdade, como Wedgwood reitera e como Horn (1982) e Rooth (1985, 1992) já haviam apontado, é possível formular um "raciocínio griceano" relativamente simples por meio do qual a "exaustividade" pode ser deduzida do foco. Adaptando ideias de Rooth e Wedwood, podemos formular este raciocínio da seguinte maneira:

(i) como vimos nos casos acima discutidos, "foco" é a asserção de UMA das alternativas de um conjunto contextualmente relevante de proposições;

(ii) por cálculo griceano similar ao das implicaturas escalares, isto é, a partir da Máxima da Quantidade (em particular, da submáxima "Faça sua contribuição tão informativa quanto requerido"), o falante implica que as alternativas não assertadas não são verdadeiras;

(iii) logo, o interlocutor conclui que apenas a proposição assertada é verdadeira e todas as alternativas pertinentes contextualmente não o são - isto é, a proposição assertada é "exaustiva”.

Esse raciocínio é suficiente para explicar por que há exaustividade em vários dos contextos acima discutidos e por que, presumir-se-ia, em muitos deles as clivadas são possíveis: o leitor pode confirmar isso reanalisando (12), (13), (15), (18) e (22). Mas o raciocínio não explica por que as clivadas não são possíveis em certos contextos discutidos, especificamente: (14), (16), (17), (19) e (21).

Para alguns destes contextos, há explicação imediata: a conhecida pressuposição que acompanha as clivadas. Como se sabe (ver PRINCE, 1978; HORN, 1982; DELIN, 1992, entre outros), as clivadas pressupõem que a proposição expressa pela oração clivada é verdadeira para algum valor correspondente ao "termo aberto" nela, cf. (23); mais genericamente, presume-se algo como (24):

(23) Era o JOÃo [ que a Maria queria encontrar ___ ]. Pressuposição: A Maria queria encontrar alguém. 
Se presumimos que a presença desta pressuposição no contexto seja uma condição de felicidade para o enunciado de uma clivada, conseguimos explicar por que alguns dos contextos acima indicados não permitem o uso destas sentenças, ainda que tais contextos satisfaçam a condição de "exaustividade". Compare-se, neste sentido, (15) com (16) e (17), por exemplo. Repito (16) como (25) abaixo:

(25) A: Os alunos chegaram?

B: O PAULO chegou. (Inferência: Os demais alunos não chegaram) B': \# Foi O PAULO que chegou.

Embora a asserção de B, sob a pressuposição de que Paulo é um dos alunos, implique exaustividade (isto é, implique que os demais alunos não chegaram), isso não é suficiente para o uso da clivada em B': a pergunta de A não indica que há uma pressuposição contextual de que alguém chegou.

Mas há exemplos que revelam que nem a combinação dos dois requisitos - de que haja uma pressuposição existencial com o caráter de (24) no contexto, e de que o constituinte clivado exclua as demais alternativas contextuais - é suficiente para caracterizar os contextos em que clivadas são usadas adequadamente. Considere-se novamente (14), abaixo repetida como (26):
(26) A: Quais dos alunos chegaram?
(Pressuposição: Alguns alunos chegaram.)
B: O PAULO chegou. ${ }^{10}$
(Inferência: Dos alunos, só o Paulo chegou.)
B': \#Foi o PAULO (que chegou).

Note-se que a pergunta de A pressupõe que alguns alunos chegaram; além disso, a asserção de B implica exaustividade (sob a assunção de que Paulo

${ }^{10}$ Um dos pareceristas observa, acerca deste enunciado: “[É] verdadeiro que, se há um acento de foco sobre o sujeito, a interpretação tende a ser a indicada no texto; contudo, há a possibilidade de imprimir ao enunciado a chamada 'entoação de continuação', que poderia ser representada na escrita pelas reticências, caso em que a interpretação só assegura a verdade da chegada para o sujeito da frase, não se pronunciando sobre o resto do conjunto (correspondente a uma interpretação como 'os outros eu não sei')." Concordo com o julgamento do parecerista, salvo por um aspecto: a meu ver, neste caso, o pitch accent sobre $o$ Paulo não é de "foco", mas de "tópico contrastivo" (cf. discussão de (9) acima). De fato, sabidamente tópicos contrastivos podem implicar "ignorância" do falante com respeito à verdade de proposições alternativas à assertada (BÜRING, 1997, 2003). 
é um dos alunos). Portanto, (26) é um contexto em que há tanto a exaustividade quanto a pressuposição requeridas pelas clivadas - no entanto, uma clivada é inadequada no contexto, cf. B'. Considere-se ainda (21), abaixo repetida como (27):

(27) [Contexto: várias pessoas em torno de uma mesa com café, chá, bolachas, etc.]

A: O que o João quer? (Pressuposição: O João quer algo.)

B: (O João quer) CAFÉ. (Inferência: O João quer café, e não chá, etc.) \# É CAFÉ (que o João quer).

A situação é basicamente a mesma que a de (26).

Para explicar estes casos, é preciso adicionar uma condição de uso às clivadas: uma pressuposição de unicidade - isto é, é preciso incorporar o "efeito da exaustividade" da clivada como parte da pressuposição caracterizada em (24). Compare-se (26) e (27) com contextos em que clivadas podem ser usadas:

(28) A: Quem chegou, o João ou o Paulo?

B: O PAULO chegou.

Foi o PAULO (que chegou).

(29) A: Qual dos alunos chegou?

B: O PAULO chegou.

B': Foi o PAULO (que chegou).
(Pressuposição: um dos dois é o único que chegou.)

(Pressuposição: só um dos alunos chegou.)

Nos contextos acima, fica claro que, quando B faz sua asserção, compartilha com A a pressuposição de que apenas um elemento satisfaz a proposição pressuposta. O que o enunciado de B faz é assertar qual das alternativas contextuais satisfaz esta proposição, e isso implica, contextualmente, que nenhuma das outras alternativas satisfaz a mesma proposição. Nestes contextos, as clivadas podem ser usadas sem problemas.

Da discussão precedente sobre o papel da "exaustividade" no uso de foco e na distribuição das clivadas, pode-se concluir que:

(i) A exaustividade não é "adicionada" ao foco informacional - é uma implicatura típica dele; a diferença com relação às clivadas pode ser, no máximo, que estas "assertam", e não "implicam”, a exaustividade (mas ver HORN, 1982 e RODRIGUES; MENUZZI, 2008, contra esta posição);

(ii) o "traço" que parece melhor explicar a distribuição das clivadas é a "pressuposição de unicidade", que está vinculada à oração clivada, e 
não ao constituinte clivado - portanto, se houvesse algo a ser adicionado à pragmática do foco informacional quando "exaustivo", seria uma propriedade da pressuposição das clivadas, e não uma propriedade de seu foco;

(iii) em suma, o elemento necessário para caracterizar "foco exaustivo ou identificacional", tal como expresso por clivadas, deveria ser um "traço" associado à pressuposição (isto é, à oração clivada), e não ao foco (isto é, o constituinte clivado). ${ }^{11}$

\section{CONCLUSÃo: FOCO E ALTERNATIVAS}

Espero ter mostrado, nas seções precedentes, que a relação entre "foco informacional", "foco contrastivo" e "foco exaustivo" é mais complicada do que se costuma presumir. Em particular, nem contraste, nem exaustividade, parecem ser adequadamente representadas por um "traço diacrítico" que se adicione a noção de "foco".

"Contraste" parece generalizar sobre um conjunto de ações que podemos fazer ao assertar uma proposição diante de um conjunto de alternativas potenciais: podemos denegar uma asserção ou uma pressuposição alheia, podemos comparar dois termos em relação a qual deles satisfaz uma condição pressuposta, etc. Vimos que as condições em que se afirma que há "contraste" podem não ser facilmente distinguíveis daquelas em que simplesmente temos foco informacional - o que, além de colocar em dúvida a ideia de que o "acento de contraste" seja distinguível do "acento de foco", sugere ainda que "contraste" pode ser gradiente (relacionado, por exemplo, com força ilocucionária e com o número de alternativas sendo "contrastadas" contextualmente).

"Exaustividade", pelo menos nos casos aqui estudados, não parece ser uma noção "gradiente" (mas ver Menuzzi e Terra, a aparecer, para discussão); mas também não é, no caso geral, uma inferência a ser "adicionada" ao foco, já que é uma "implicatura default" de foco - antes, é a ausência de

${ }^{11}$ O caráter pressuposicional da "exaustividade" das clivadas já fora observado pela literatura anteriormente. Ele está por trás do tratamento de Horn, segundo o qual a exaustividade seria uma "implicatura conversacional generalizada", bem como por trás da análise de Hedberg (2000), para quem a oração clivada é interpretada basicamente como uma descrição definida. Mais recentemente, Wedgwood et al. (2006) explicitam uma análise pressuposicional que parece ser equivalente à de Hedberg. Em trabalho ainda em andamento (MENUZZI; TERRA, a sair), identificamos vários "efeitos de exaustividade" em clivadas que não parecem compatíveis com a pressuposição de unicidade, mas estamos incertos ainda do significado destes fatos. Por isso, deixamos a discussão para um trabalho futuro, específico sobre os diferentes tipos de "efeito de exaustividade". 
exaustividade que exige ser "marcada" contextualmente. Além disso, o efeito de exaustividade mais característico das clivadas - o que, presumivelmente, corresponderia ao "traço inerente" desta construção e, portanto, seria aquilo que poderia ser "adicionado" ao foco informacional - não está na asserção de identidade entre constituinte clivado e "valor da variável aberta" da oração clivada. Antes, trata-se da "pressuposição de unicidade" que está associada apenas à oração clivada. É difícil compreender em que sentido pressuposições poderiam ser representadas por "traços" a serem checados; mais ainda no caso que discutimos: teria de ser um traço "checado" pela oração clivada, e não pelo constituinte clivado (que é o constituinte que se move para a checagem de traços nas análises correntes).

Toda a argumentação precedente parte de um pressuposto básico, que segue a análise proposta por Rooth $(1985,1992)$ para a semântica do "foco": a de que o papel do foco é evocar um conjunto de proposições composto pela substituição do termo focalizado por termos alternativos contextualmente relevantes. Os demais efeitos de foco podem ser derivados desta base: a asserção de uma das alternativas, por implicatura de quantidade, resulta na exclusão das demais, do que se obtém o efeito de exaustividade; do mesmo modo, a asserção de foco num contexto em que uma alternativa contrária havia sido previamente assertada ou pressuposta resultará em um ato de denegação, portanto "correção" ou "contraste"; etc. Ou seja, seguindo Rooth, pode-se postular que a função básica do foco-sinalizado pelo "acento mais proeminente" da sentença - seria precisamente evocar um conjunto de alternativas contextuais.

Wedgwood (2005), tendo como background teórico a Teoria da Relevância (“RT”, cf. SPERBER; WILSON, 1986), propõe, entretanto, uma análise ainda mais geral. Discutindo as propostas de Rooth, Wedgwood diz: "From a pragmatic point of view, such an analysis seems to involve somewhat inverted reasoning. Alternatives to (the denotation of) some expression are invoked in the course of interpretation to the extent that they are relevant. The logic of RT suggests that a grammatically triggered evocation of alternatives is therefore unnecessary" (p. 101; ênfase minha). Portanto, para Wedgwood, o "acento de foco" não tem a função de "evocar um conjunto de alternativas relevantes contextualmente" - isto é, de indicar qual conjunto de alternativas seria pertinente; antes, elas são evocadas "na medida em que são relevantes" - isto é, se indicadas como tal pelo contexto. Wedgwood parece ter em mente algo como o proposto anteriormente por Sperber e Wilson (1986) e Breheny (1998): "The essence of the analysis is that phonological stress indicates information to which the addressee is intended to pay particular attention (Breheny draws an analogy to physical pointing as a way of making the purpose of an utterance manifest)" (p. 102). 
A meu ver, é difícil distinguir esta posição da posição expressa mais formalmente por Rooth. (Para maiores detalhes, ver WEDGWOOD 2005, p. 101 e ss.; p. 119 e ss.; e p. 134 e ss.) Mas tomemo-la numa versão extrema: o termo assinalado por "acento de foco" só indicará um "conjunto de alternativas contextualmente relevantes" se tiver correlatos contextuais que possam ser concebidos, em algum sentido, como alternativas relevantes a ele. Em outros termos: "foco" é, apenas, uma "marca icônica de relevância"; na presença contextual de um conjunto de alternativas, tem todas as demais consequências que acima discutimos.

Resumindo a diferença entre a posição de Rooth e a de Wedgwood, podemos dizer que, para Rooth, a evocação de um conjunto de alternativas é o elemento irredutível do foco; para Wedgwood, não; foco apenas "sinaliza relevância". No que segue, procurarei mostrar que há razões iniciais para acreditar que a posição de Rooth pode estar correta; mas trata-se de uma discussão difícil, e é claro que investigação muito mais detalhada será necessária "to settle the score".

Para começar, a hipótese de Rooth explica uma outra propriedade pragmática do "foco informacional" que é, via de regra, neglicenciada, mas que é facilmente apreensível: a de que "buscar relevância", no caso de foco, normalmente significa "buscar um conjunto de alternativas relevantes e excluí-las", e não qualquer outro tipo de associação pertinente. Isso acontece mesmo em contextos em que aparentemente não há um "conjunto de alternativas relevantes" evocado - e em que a exaustividade, portanto, poderia, à primeira vista, não ser pertinente. Mesmo nestes contextos, o fato é que o interlocutor se esforça por buscar um conjunto de alternativas em relação ao qual o foco do enunciado se torne relevante. Retornemos ao exemplo (19), repetido em (30) abaixo, em que à primeira vista não há exaustividade porque não há um conjunto de alternativas relevantes:

(30) [Contexto: B está contando a A que foi a uma festa.]
A: Quem você encontrou lá?
B: Eu encontrei O PAULO lá.
B': \# Foi O PAULO que eu encontrei lá.

Como já apontei, o enunciado de B não implica exaustividade no sentido de que B só encontrou Paulo na festa, e mais ninguém. Mas certamente implica que, das pessoas que são de algum modo relevantes para as relaçóes de $A e$ $B$ (por exemplo, as pessoas que são amigas de A e B), B só encontrou Paulo. Ou seja: há exaustividade em relação a algum conjunto de alternativas evocado por "o Paulo", embora este conjunto de alternativas não pareça imediatamente relevante ou saliente no contexto. Note-se, ainda, para não 
perder a ocasião: não apenas há exaustividade como há a pressuposição de que B encontrou alguém na festa; mas não há pressuposição de unicidade, e por isso a clivada não é apropriada. Compare-se o contexto (30) com o contexto em (31) abaixo:

(31) [Contexto: A e B estavam numa festa. Falam do momento em que A se retirou, quando pareceu a $B$ estar procurando por alguém.]

A: E aquela hora que você deu uma saída: quem você tava procurando?

B: (Eu tava procurando) O PAULO.

Era O PAULO (que eu estava procurando).

(31) difere minimamente de (30) pelo fato de A pressupor que B estava procurando uma pessoa específica, pressuposição confirmada pela resposta e, portanto, compartilhada entre A e B. O contraste entre (31) e (32) confirma as observações da seção anterior sobre a relevância da pressuposição de unicidade (cf. (31)), e não do "efeito de exaustividade" por si só, ou combinado com uma pressuposição mais fraca de "existência" (cf. (30)).

Em (32) abaixo ilustro mais um caso em que A procurará por um conjunto de alternativas ao termo em foco na asserção de B, embora possivelmente nada no contexto requeira isso:

(32) A: O João tá muito gordo! O que ele anda comendo?!

B: Ele anda comendo MUITA MASSA.

É claro que, na interpretação mais natural do enunciado de B - isto é, na ausência de informações contextuais adicionais -, A não inferirá que João está comendo "muita massa" e só - isto é, que não esteja comendo outras coisas. Antes a inferência mais natural parece ser: "entre as várias coisas que poderia comer para engordar, o que João está comendo é muita massa (e não doces, pão, etc.)". Isto é, novamente há, sim, um "efeito de exaustividade" ou de "exclusão de alternativas relevantes", ainda que nada no contexto torne tais alternativas, ou a necessidade delas, saliente.

Wedgwood (2005), na verdade, baseia sua proposta numa possível diferença entre "foco estreito" (de constituintes) e "foco largo" (projetado, de VP, em estruturas de tópico/comentário): "foco largo" não implicaria exaustividade - e, portanto, enfraqueceria a tese de que a função de foco é evocar um conjunto de alternativas. (Ver WEDGWOOD, 2005, p. 107 e ss.; p. 138 and ss.) Mas me parece que a busca por "exaustividade" - "exclusão de um conjunto relevante de alternativas" - também vale para os casos de "foco largo". Considere os contextos em (33) e (34) abaixo: 
(33) A: (O João não acabou o almoço ainda?!) O que ele fez hoje de manhã?

B: Ele [foi AO BANCO].

(= o que fez entre as coisas que poderia fazer além das que normalmente faz.)

(34) [A e B conversam depois de terem encontrado o João.]

A: Puxa, como o João está feliz. Por que será?

B: Ele [comprou UM CARRO NOVO].

(= o que fez entre as coisas que poderia fazer para ficar feliz.)

É de se notar que não seria uma resposta pertinente em (33), por exemplo, "Ele escovou os dentes" - isto é, algo que João faça rotineiramente não atrapalharia, presumivelmente, a organização de seu tempo. Concomitantemente, este tipo de alternativa não é excluído: isto é, há um efeito de exaustividade em (33), mas não que exclua alternativas como "João escovou os dentes, João tomou café, etc." As alternativas excluídas, por implicatura, são aquelas que poderiam alterar a rotina do João e, portanto, a organização de seu tempo: por exemplo, "Ele teve de atender um paciente que não tinha hora marcada", ou "Ele teve de levar o carro na oficina", etc. É claro que observações similares se aplicam a (34). Portanto, "foco largo", ou de VP, também parece, no caso normal, implicar algum "efeito de exaustividade" - mesmo quando não há um conjunto óbvio de alternativas salientes no contexto.

Para concluir, comparemos os casos em (35) e (36) abaixo. O contexto em (35) segue o padrão descrito por Wedgwood: embora não expressas verbalmente, há alternativas relevantes manifestas no contexto para a alternativa assertada; e o resultado é o esperado: a asserção de uma das alternativas exclui as que estão manifestas:

(35) [Contexto: A e B sabem que Paulo trata de animais no Zoo; estão diante das jaulas dos tigres e das panteras.]

A: Será que o Paulo está por perto?

B: Ele alimenta OS LEÕES.

(Inferência: provavelmente ele não está por perto.)

Mas (36) é o contrário: não há alternativas à assertada "manifestas no contexto", ou melhor, a única "alternativa manifesta" é exatamente a que é assertada; outras alternativas não manifestas não parecem obviamente relevantes:

(36) [Contexto: idem, mas estão diante das jaulas dos leões.]

A: Será que o Paulo está por perto?

B: Ele alimenta OS LEÕES.

(Inferência: provavelmente ele está por perto.) 
Mas é claro que as alternativas são relevantes, ainda que não "manifestas contextualmente": se Paulo alimenta os leões, então normalmente ele estará próximo à jaula dos leões, e não próximo à jaula de outros animais - tigres, panteras, etc. Logo, a implicatura do enunciado de B é que "Paulo deve estar próximo à jaula dos leões, e não à dos tigres, ou à das panteras, etc." Isto é, novamente há, sim, efeito de exaustividade em relação a alternativas relevantes contextualmente - ainda que estas não sejam "manifestas" no contexto.

Minha conclusão, desta discussão toda, é que Rooth está certo: a função básica de "foco" não é, simplesmente, sinalizar alguma noção ampla de "material relevante": antes, é sinalizar que uma certa alternativa - a assertada - "opera ou afeta um conjunto de alternativas relevantes contextualmente". E, nos casos acima, "operar ou afetar este conjunto" significa "ser a alternativa verdadeira, à exclusão das demais" - isto é, "implicar exaustividade". Mas é possível que haja outras maneiras de a alternativa assertada operar pragmaticamente sobre o "conjunto contextualmente relevante de alternativas" (cf. o que digo na nota 11 acima).

\section{REFERÊNCIAS}

BELLETTI, A. Answering Strategies: New Information Subjects and the Nature of Clefts. In: . Structures and Strategies. Nova Iorque: Routledge, 2009. p. 242-265.

BREHENY, R. Interface economy and focus. In: ROUCHOTA, V.; JUCKER, A.H. (Eds.). Current Issues in Relevance Theory. Amsterdam: John Benjamins, 1998. p. 105-139.

BÜRING, D. The Meaning of Topic and Focus: the $59^{\text {th }}$ Street Bridge Accent. Nova Iorque: Routledge, 1997.

. On D-Trees, Beans, and B-Accents. Linguistics \& Philosophy, v. 26, n. 5, p. 511-545, 2003.

CHOMSKY, N. Deep Structure, Surface Structure, and Semantic Interpretation. In: STEINBERG, D.; JAKOBOVITS, L. (Eds.). Semantics: An Interdisciplinary Reader in Philosophy, Linguistics and Psychology. Cambridge: Cambridge University Press, 1971. p. 183-216.

DELIN, J. Properties of $i t$-cleft presupposition. Journal of Semantics, v. 9, p. 289-306, 1992.

ERTESCHIK-SHIR, N. Information Structure. Oxford: Oxford University Press, 2007.

GUSSENHOVEN, C. Types of Focus in English. In: LEE, C.; GORDON, M.; BÜRING, D. (Eds.). Topic and Focus: Cross-linguistic Perspectives on Meaning and Intonation. Heidelberg, New York, London: Springer, 2007. p. 83-100.

HARTMANN, K. Focus and Emphasis in Tone and Intonation Languages. In: STEUBE, A. (Ed.). The discourse potential of underspecified structures. Berlin: W. de Gruyter, 2008. p. 389-411.

HEDBERG, N. The Referential Status of Clefts. Language, v. 76, p. 891-920, 2000.

HORN, L. Exhaustiveness and the semantics of clefts. In: BURKE, V.; PUJETOVSKY, J. (Eds.). Proceedings of NELS 11. Amherst: GLSA, 1981. p. 125-142.

JACKENDOFF, R. Semantics in Generative Grammar. Cambridge, MA: MIT Press, 1972. 
KISS, K. Identificational focus and information focus. Language, v. 74, p. 245-273, 1998.

KRAHMER, E.; SWERTS, M. On the alleged existence of contrastive accents. Speech Communication, v. 34, p. 391-405, 2001.

LAMBRECHT, K. Information Structure and Sentence Form: Topic, Focus, and the mental representations of discourse referents. Cambridge (Ingl.): Cambridge University Press, 1994.

MENUZZI, S.; RODRIGUES, G. R. Tópicos contrastivos e contraste temático: um estudo do papel discursivo da articulação informacional. Caderno de Estudos Linguísticos, Campinas: UNICAMP, v. 52, p. 233-253, 2010.

; TERRA, M. T. Efeitos de "exaustividade" em clivadas - um estudo de corpus. A aparecer. Programa de Pós-Graduação em Letras, UFRGS, Porto Alegre, 2012.

MIOTO, C. Focalização e quantificação. Revista Letras, Curitiba: UFPR, v. 61, p. 169-189, 2004.

PIERREHUMBERT, J.; HIRSCHBERG, M. The Meaning of Intonational Contours in the Interpretation of Discourse. In: COHEN, P. R. et al. (Eds.). Intentions in Communication. Cambridge, MA: MIT Press, 1990. p.271-311.

PRINCE, E. A comparison of WH-clefts and it-clefts in discourse. Language, v. 54, p. 883-906, 1978.

QUAREZEMIN, S. Estratégias de focalização no Português brasileiro: uma abordagem cartográfica. Tese (Doutorado em Linguística) - Programa de Pós-Graduação em Linguística, UFSC, Florianópolis, 2009.

RIZZI, L. The fine structure of left periphery. In: HAEGEMAN, L. (Ed.). Elements of Grammar. Dordrecht: Kluwer, 1997. p. 281-337.

RODRIGUES, G. R.; MENUZZI, S. M. Pressuposição, exaustividade e denegação nas clivadas. In: ENCONTRO DO CELSUL, 8., 2008, Porto Alegre. Anais... Porto Alegre: UFRGS, 2008. Disponível em: <https://sites.google.com/site/smenuzzi/artigos-hand-outs-etc>.

:___ . Articulação informacional. In: PIRES DE OLIVEIRA, R.; MIOTO, C. (Orgs.). Per-

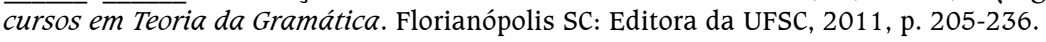

ROOTH, M. Association with Focus. Tese (Doutorado) - University of Massachusetts, Amherst, 1985. . A theory of focus interpretation. Natural Language Semantics, v. 1, p. 75-116, 1992.

ROSA DA SILVA, F. Foco e relações de escopo: um estudo de caso no português brasileiro. Dissertação (Mestrado) - USP, São Paulo, 2012.

SPENADER, J.; MAIER, E. Contrast as Denial in multi-dimensional semantics. Journal of Pragmatics, v. 41, n. 9, p. 1707-1726, 2009.

SPERBER, D.; WILSON, D. Relevance: Communication and Cognition. Oxford: Blackwell, 1986.

UMBACH, C. Contrast and Information Structure: A focus-based analysis of but. Linguistics, v. 43, p. 207-232, 2005.

WEDGWOOD, D. Shifting the Focus: From Static Structures to the Dynamics of Interpretation. Oxford: Elsevier, 2005.

; PETHÕ, G; CANN, R. Hungarian "focus position" and English it-clefts: the semantic underspecification of "focus" readings. Ms., Dept. of Linguistics, University of Edinburgh, 2006.

ZUBIZARRETA, M. L. Prosody, Focus, and Word Order. Cambridge, MA: MIT Press, 1998.

Submetido em: $18 / 11 / 2012$

Aceito em: 22/02/2013 